\title{
Stressed Patients, Stressed Physicians and the Need for Mind-Body Medicine
}

\author{
Andreas Michalsen ${ }^{a, b}$ \\ ${ }^{a}$ Department of Internal and Integrative Medicine, Immanuel Hospital Berlin, \\ ${ }^{\mathrm{b}}$ Institute of Social Medicine, Epidemiology, and Health Economics, Charité University Medical Center Berlin, Germany
}

The idea that the mind is important to maintain health and to recover from illness goes back to the earliest medical systems. However, this idea is still a matter of serious discussions about self-healing and placebo effects. After the mind and the body had been conceptually separated during the Renaissance, a reunification took place in the 20th century through several scientific approaches, i.e. psychosomatics and psychoneuroimmunology. In contrast, traditional systems like Ayurvedic medicine, traditional Chinese medicine, and European naturopathy have always focused on a continuum of mind and body. Moreover, especially in the East, relaxation methods such as Tai chi, yoga, or meditation were integral parts of the therapeutic approach. In the recent past, the field of mind-body medicine has been defined more precisely and integrated into complementary medicine by the U.S. National Institutes of Health (http:// nccam.nih.gov/health/whatiscam/\#mindbody). Furthermore, mind-body medicine has received increasing attention by the public and the lay press.

Mind-body medicine is of course nothing new. - What is new is the integrating entity, the legitimization of research in this field and the inclusion of mind-body programs into the treatment approaches offered by major medical institutions.

Mind-body medicine is based on two principal notions. Firstly, that stress plays a major role in the pathogenesis of disease and, secondly, that relaxation methods and mindfulness in life are beneficial to health. Solid evidence for both assumptions is increasing.

\section{Stress and Disease}

Since the first description of the flight-or-fight response, also called the 'acute stress response' by Harvard re- searcher Walter Cannon in the 1920s, an abundance of physiological and clinical studies has revealed the pathways of distress to disease. Experimental and epidemiological studies have shown that stress considerably contributes to myocardial infarction, stroke, degenerative neurological disease, pain syndromes, inflammatory bowel disease, delayed wound healing, depression and cancer. For example, the INTERHEART study has shown that up to $30 \%$ of myocardial infarctions might be caused by stress in the recent past [1]. Experimental research has shown how psychosocial stress can increase cellular oxidative stress, activate signal transduction [2] and modify gene expression. Recent studies have found that objective stress (e.g., years of care-giving) and perceived life stress were both related to shorter telomere length, indicative of bodily aging [3].

On the other hand, more and more people in Western societies feel distressed and under pressure. A recent survey of one of the largest German health insurance companies has revealed that $80 \%$ feel stressed frequently, and $30 \%$ feel stressed most of the time (http://www.tk.de/tk/medienservice/archiv-2009/mai09-stress/164488). Other studies have shown that $60-80 \%$ of all physician visits are for stress-related complaints. And if that was not all, most physicians and health professionals feel distressed themselves. In the United States up to $60 \%$ of practicing physicians report symptoms of burn-out [4]. Physician's burnout has been linked to poorer quality of care, increased medical errors, substance abuse and decreased ability to express empathy.

\section{Relaxation and Health}

Stress reduction in the concept of mind-body medicine aims to elicit the relaxation response by means of different

\section{KARGER}

Fax +497614520714

Information@Karger.de

www.karger.com (c) 2010 S. Karger GmbH, Freiburg

Accessible online at:

www.karger.com/fok
Prof. Dr. med. Andreas Michalsen

Abt. für Naturheilkunde, Klinik für Innere Medizin

Immanuel Krankenhaus Berlin

Königstr. 53, 14109 Berlin, Germany

Tel. +30 80505-691, Fax -692

a.michalsen@immanuel.de 
techniques. Further components of stress reduction are strengthening of resiliency through cognitive skills training, social support and pro-social behavior, optimism and spirituality. Finally, successful stress reduction and consecutive mindfulness are said to support lifestyle modification resulting in improved nutrition and more exercise. Evidence of the last years suggests that of the various types of relaxation techniques especially meditation, yoga and Tai chi are effective and useful in the management of chronic disease. Recent results on mind-body therapies include [5]:

- Yoga leads to lasting pain relief and improved function in patients with chronic back pain.

- Tai chi may be a useful treatment for fibromyalgia [6].

- Meditation in addition to usual care contributes to a lower death rate in people aged $>55$ years with high blood pressure [7].

- Meditation effectively lowers blood pressure.

- Meditation can be an effective strategy to prevent the cognitive decline in normal aging.

- Meditation / body scan practice is associated with systematic changes of gene expression in molecular pathways involved in cellular metabolism, oxidative phosphorylation / generation of reactive oxygen species and response to oxidative stress.

- Practicing yoga has a positive effect on chronic insomnia and promotes a rapid stress reduction.

- Mindfulness-based stress reduction can relieve symptoms of anxiety in patients with anxiety disorder and improve well-being in patients with rheumatoid arthritis and osteoarthritis

\section{The Need for Research in Mind-Body Medicine}

Despite promising preliminary evidence, more sound research on the effectiveness and the mechanisms of mindbody medicine is urgently required. Trials executed to date only included small sample sizes. Little is known about the optimum 'dose' (practicing time), comparative effects of different relaxation methods and existing mind-body programs. Furthermore, adherence may be an issue when translating mind-body medicine from highly selected motivated study patients to the general population. Outcome research should also focus on the sustainability and feasibility of existing programs and on the best educational methods.

We also should not forget the aspect of spirituality which underlies traditional relaxation methods. Numerous studies have found that spiritual beliefs and attitudes may have positive effects on health. Of course, it is possible to adopt mind-body techniques on a strictly secular background. Yet, a spiritual quality in disease coping could further enhance its effects on health and healing.

Most probably, the demand for mind-body medicine will continue to increase, due to the ongoing acceleration of daily life, work and health care. A pioneering day-care hospital for mind-body medicine, supported by health insurance companies, was developed at the Kliniken EssenMitte, Germany, and now broadly established at Charité University Medicine / Immanuel Hospital Berlin, Germany. The experience gained at these institutions and the increasing demand for mind-body medicine illustrate impressively how neatly this approach meets the current needs of patients. However, it may now be the time to go further and to call for a widespread implementation of mind-body medicine beyond complementary medicine, especially in medical units that treat chronic diseases such as metabolic and cardiovascular disorders, hypertension, cancer and chronic pain disorders. Such an implementation should, of course, be accompanied by randomized intervention trials. As an example, an ongoing randomized trial at Charité University Medicine Berlin evaluates the effectiveness of meditation in patients with chronic back pain.

What perhaps may motivate physicians and researchers to implement mind-body medicine could be the fact, that the treatment is good for the therapist, too. A recent trial has shown that psychotherapists performed better if they practiced meditation before the treatment sessions [8]. Moreover, participation of primary care physicians in a mindfulness program was associated with sustained improvements in well-being and attitudes towards patientcentered care [4].

Therefore, patients and physicians should not hesitate and welcome mind-body medicine in modern health. It is highly probable that stress reduction and comprehensive lifestyle modifications as required in the majority of our patients will only be successful, if we manage to integrate more broadly scientifically proven mind-body medicine into conventional medicine.

\section{Acknowledgment}

This work was supported by the Else Kröner-Fresenius-Stiftung, Bad Homburg, through the project 'Effectiveness of meditation in patients with chronic back pain'. 


\section{References}

1 Rosengren A, Hawken S, Ounpuu S, Sliwa K, Zubaid M, Almahmeed WA, Blackett KN, Sitthiamorn C, Sato H, Yusuf S: Association of psychosocial risk factors with risk of acute myocardial infarction in 11,119 cases and 13,648 controls from 52 countries (the INTERHEART study): case-contro study. Lancet 2004;364:953-62.

2 Bierhaus A, Wolf J, Andrassy M, Rohleder N, Humpert PM, Petrov D, Ferstl R, von Eynatten M, Wendt T, Rudofsky G, Joswig M, Morcos M, Schwaninger M, McEwen B, Kirschbaum C, Nawroth PP: A mechanism converting psychosocial stress into mononuclear cell activation. Proc Natl Acad Sci U S A 2003;100:1920-5.

$>3$ Epel E, Daubenmier J, Moskowitz JT, Folkman S, Blackburn E: Can meditation slow rate of cellular aging? Cognitive stress, mindfulness, and telomeres. Ann N Y Acad Sci 2009;1172:34-53.
Krasner MS, Epstein RM, Beckman H, Suchman AL, Chapman B, Mooney CJ, Quill TE: Association of an educational program in mindful communication with burnout, empathy, and attitudes among primary care physicians. JAMA 2009;302: 1284-93.

5 Michalsen A: Wissenschaftliche Bewertung der Mind-Body-Medizin; in Paul A, Dobos G (eds): Mind-Body-Medizin. München, Elsevier, in press.

6 Wang $\mathrm{C}$, Schmid $\mathrm{CH}$, Rones R, Kalish R, Yinh J, Goldenberg DL, Lee Y, McAlindon T: A randomized trial of tai chi for fibromyalgia. N Engl J Med 2010;363:743-754.
7 Schneider RH, Alexander CN, Staggers F, Rainforth M, Salerno JW, Hartz A, Arndt S, Barnes VA, Nidich SI: Long-term effects of stress reduction on mortality in persons $>$ or $=55$ years of age with systemic hypertension. Am J Cardiol 2005;95: 1060-4.

8 Grepmair L, Mitterlehner F, Loew T, Bachler E, Rother W, Nickel M: Promoting mindfulness in psychotherapists in training influences the treatment results of their patients: a randomized, double-blind, controlled study. Psychother Psychosom 2007;76:332-8. 